\title{
Uma análise da política de educação ambiental da Bahia
}

O direito à Educação Ambiental (EA) está consagrado na Constituição Federal de 1988 e em leis infraconstitucionais, a exemplo da Lei $9795 / 99$, que instituiu a Política Nacional de Educação Ambiental-PNEA, a qual serviu de referência para a criação da Lei 12.056/20011, responsável pela implementação da Política Estadual de Educação Ambiental da Bahia - PEEA/BA. O presente artigo visa fazer uma análise da PEEA/BA e de seu recente Decreto Regulamentar(DR) no 19.083 de 06 de junho de 2019, demonstrando as suas especificidades, com enfoque na Educação Ambiental Formal(EAF) e tecendo comentários à luz dos documentos oficiais e da literatura da educação ambiental existente. Para tanto, foi realizada uma pesquisa documental e bibliográfica, abordando a Constituição Federal brasileira de 1988, Leis e outras normas de hierarquia inferior, Programas Governamentais e Institucionais sobre a EA em nível mundial, nacional e estadual, com ênfase na PEEA/BA, livros e artigos científicos nas bases de dados Scielo, Google Acadêmico e Science Direct. Com esta pesquisa, evidenciou-se a relevância da PEEA/BA como mais um instrumento em prol da EA formal, de produção textual e algumas concepções mais amplas que a PNEA, porém com lacunas e conceitos a serem sanados, e o grande desafio que se apresenta é a garantia da sua efetividade, tendo como primeiro passo conhecer e interpretar a Lei como um dos requisitos para que as suas diretrizes e metas legalmente estabelecidas possam ser concretizadas.

Palavras-chave: Conhecimento; Desafios; Ensino formal; Legislação; Meio Ambiente.

\section{An analysis of Bahia's environmental education policy}

The right to Environmental Education (EA) is enshrined in the Federal Constitution of 1988 and in non-constitutional laws, such as Law $9795 / 99$ establishing the National Environmental Education Institute (PNAE), which served as a reference for the creation of 12.056/20011, responsible for implementing the State Environmental Education Policy from Bahia - PEEA/BA. This article aims to make an analysis of PEEA / BA and its recente Regulatory Decree (DR) no. 19.083 of June 6, 2019, demonstrating its specificities, focusing on Formal Environmental Education (EAF) and making comments to the light of the official documents and literature on existing environmental education. For that, it was a documental and bibliographical research was conducted, addressing the Brazilian Federal Constitution of 1988, Laws and other norms of inferior hierarchy, Programs And Governmental Institutions on EE at the world, national and state levels, with PEEA/BA, books and scientific articles in the Scielo, Google Scholar and Science Direct. With this research, it has been showed the relevance of PEEA/BA as another instrument in favor of formal EA, of textual production and some broader conceptions compared to the PNEA, however with lacunes and concepts to be remedied, and the great challenge that it presents, is the guarantee of its effectiveness, having as a first step to know and interpret the Law as one of the requirements for its legally established guidelines and goals to be achieved.

Keywords: Knowledge; Challenges; Formal education; Legislation; Environment.

Topic: Educação Ambiental

Reviewed anonymously in the process of blind peer.
Received: $10 / 08 / 2019$

Approved: 28/09/2019
Regina Cláudia Nascimento (iD)

Universidade do Estado da Bahia, Brasil

http://lattes.cnpq.br/5711829477740288

http://orcid.org/0000-0001-9147-8613

regclaudia1@hotmail.com

Eliane Maria de Souza Nogueira (iD)

Universidade do Estado da Bahia, Brasil

http://lattes.cnpq.br/4084512070761915

http://orcid.org/0000-0003-2681-7601

emsnogueira@gmail.com

Paulo Roberto Ramos

Universidade Federal do Vale do São Francisco, Brasil

http://lattes.cnpq.br/9107135900230723

http://orcid.org/0000-0003-3684-0960

paulo.roram@gmail.com
Referencing this:

NASCIMENTO, R. C.; NOGUEIRA, E. M. S.; RAMOS, P. R.. Uma análise da política de educação ambiental da Bahia. Revista Ibero Americana de Ciências Ambientais, v.10, n.5, p.331-344, 2019. DOI: http://doi.org/10.6008/CBPC2179-6858.2019.005.0029

DOI: 10.6008/CBPC2179-6858.2019.005.0029 


\section{INTRODUÇÃO}

O debate acerca das questões ambientais evidencia o direito à Educação Ambiental (EA) como meio para a persecução do ambiente ecologicamente equilibrado, previsto na Carta Magna de 1988. Este ambiente saudável e sustentável é um direito fundamental, difuso e humano de terceira geração. Fundamental porque é garantia mínima à condição de ser humano; difuso porque deve ser assegurado a toda a coletividade; de terceira geração, porque sucede o percurso histórico dos direitos humanos de primeira e segunda gerações, reivindicado por lutas e consolidado de acordo com as necessidades humanas coletivas, como o direito ao meio ambiente (ROSA et al., 2018).

Pode-se dizer, ainda, que o meio ambiente ecologicamente equilibrado atende a um dos fundamentos do Estado Democrático de Direito, tal qual a dignidade da pessoa humana (BRASIL, 1988). Uma vida digna se consolida em uma relação humana com a natureza de respeito, zelo e reconhecimento das limitações naturais. Para isso, há de se fazer presente a educação ambiental, pois na visão de Cosenza et al. (2014), a educação constitui-se como prática social de empoderamento e tomada de decisões na perspectiva de defesa dos direitos humanos, tal qual o direito ao meio ambiente íntegro.

A afirmação dos direitos ecológicos na legislação ambiental brasileira ocorreu através de um longo processo legislativo-ambiental, desde a época da colonização, dividido em 3(três) fases. A primeira, da exploração desregrada, de 1500 a meados do século XX, quase isenta de normas legislativas sobre os recursos naturais, de cunho estritamente econômico e relacionadas à propriedade. A segunda, fase fragmentária, da década de 1960 até a edição da Política Nacional do Meio Ambiente - PNMA (Lei 6938/81), impôs normas legais à exploração de determinadas categorias de recursos naturais com fins econômicos e não ao meio ambiente como um todo, com predominância do utilitarismo (BENJAMIN, 1999, citado por SARLET et al., 2017).

A terceira fase do direito ao meio ambiente íntegro, denominada holística, deu-se a partir da PNMA, em que o meio ambiente passou a ter garantia da sua proteção de forma integral, constituindo-se um bem jurídico autônomo, além de ter seu valor ampliado na Carta Magna de 1988, no que se chama "constitucionalização da proteção ambiental" (BENJAMIN, 1999, citado por SARLET et al., 2017), denotando que a defesa do meio ambiente ecologicamente equilibrado é algo recente na história política e legislativa brasileira.

Foi a partir da fase holística do direito ambiental brasileiro que a EA apresentou-se fortemente como um instrumento de potencialização da causa ambiental. Dentro desse contexto, o marco legal de maior relevância depois da Constituição Federal de 1988 foi a criação da Política Nacional de Educação Ambiental-PNEA, instituída pela Lei no 9795/99, que serviu de referência, em tese, para o trabalho sobre educação ambiental desenvolvido nas escolas públicas e privadas do país, em todos os níveis e modalidades de ensino, de forma transversal e interdisciplinar (BRASIL, 1999).

Com base na PNEA, alguns estados brasileiros criaram suas leis específicas sobre a EA, em razão da competência suplementar atribuída aos estados para legislar sobre matéria ambiental, concedida pela 
Carta Magna de 1988, a exemplo do estado da Bahia, que instituiu a Política Estadual de Educação Ambiental-PEEA/BA, através da Lei 12.056 de 07 de janeiro de 2011 e seu recente Decreto Regulamentar no 19.083 de 06 de junho de 2019. Depois de sancionada, promulgada e publicada, sem vacatio legis, a Lei de EA da Bahia passou a ter vigência, ou seja, pôde ser aplicada e servir de referência oficial para os programas, projetos e ações de todo o território baiano, em todas as esferas de poder.

Convém mencionar que uma Lei sancionada é aquela em que o chefe do poder executivo aprova depois de votada e aprovada no poder legislativo; promulgada, quando é declarada a existência da lei e ordenada a sua execução, feita pelo chefe do poder executivo; a publicação é o complemento da promulgação e, normalmente, a lei entra em vigor a partir da data em que é publicada; Vacatio legis é uma expressão latina que significa vacância da lei, correspondendo ao período entre a data da publicação de uma lei e o início de sua vigência, vindo expressa no final da Lei da seguinte forma: "esta lei entra em vigor após decorridos (o número de dias) de sua publicação oficial (BRASIL, 2019).

As áreas temáticas abordadas pela lei são: a Educação Ambiental no Ensino Formal; a Educação Ambiental Não-Formal; a Educação Ambiental na Gestão das Águas; a Educação Ambiental no Saneamento Ambiental; a Educação Ambiental na Gestão das Unidades de Conservação; a Educação Ambiental na Gestão Municipal; Educação Ambiental para o Licenciamento e a Educomunicação Socioambiental (BAHIA, 2011), dentre as quais, o ponto central de discussão da presente pesquisa é a educação ambiental formal.

Vale ressaltar que, antes da promulgação da PEEA/BA, já existia na Bahia, desde o ano de 2010, em sua 1a edição, o Programa de Educação Ambiental do Sistema Educacional da Bahia-ProEASE, responsável por estabelecer a orientação da práxis educativa ambiental das escolas no sentido da sustentabilidade nas relações sociedade-natureza (BAHIA, 2015). Contudo, não se sabe se a existência desse referencial teórico foi determinante para a realização de um trabalho efetivo de educação ambiental nas unidades de ensino do Estado.

Feitas essas considerações, o estudo visa fazer uma análise do texto da Lei 12.056/2011 e o seu Decreto Regulamentar no 19.083 de 06 de junho de 2019, apresentando os acontecimentos e documentos relevantes que asseguram o direito à EA como instrumento de potencialização do meio ambiente saudável e sustentável; os conceitos, princípios, objetivos, diretrizes, instrumentos, órgãos de gestão (OG) e execução da Lei, com ênfase na área temática da EAF, na busca de se conhecer, compreender e refletir sobre a positivação da norma, dado que a questão ambiental é complexa e muitas vezes condicionada por interesses políticos e econômicos que mitigam ou impedem a concretude dos dispositivos legais.

\section{METODOLOGIA}

Esta pesquisa constitui-se em uma revisão de literatura documental e bibliográfica, embasada em documentos legislativos, governamentais e institucionais contendo os preceitos da EA em níveis mundial, nacional e estadual, com ênfase nos programas e normas legais de EA da Bahia, complementada com livros e artigos científicos nas bases de dados Scielo e Google Acadêmico.

Os dados obtidos em documentos institucionais e legais sobre a EA se deram através da via digital, 
em sites de órgãos e programas governamentais, e livros impressos contendo o Programa de Educação Ambiental da Bahia (PEA/BA) e o Programa de Educação Ambiental do Sistema Educacional da Bahia (ProEASE), levando em consideração que a pesquisa documental deve atentar a três aspectos, que foram cumpridos pela investigadora: a escolha dos documentos, o acesso a eles e a sua análise (GODOY, 1995).

A seleção bibliográfica baseou-se em artigos e livros sobre a temática da EA com relações pertinentes à Lei de Educação Ambiental da Bahia (Lei 12.056/2011). Os dados obtidos foram analisados qualitativamente, passando pela pré-análise, exploração do material e resumo dos resultados obtidos, com base na análise de conteúdo de Bardin (2002).

\section{DISCUSSÃO TEÓRICA}

\section{Contributos para o direito à educação ambiental}

Diversos eventos internacionais contribuíram para a elaboração da legislação da educação ambiental brasileira. A década de 70 (setenta) é considerada de grande importância nessa seara, devido à realização de eventos importantes, como: a Conferência Internacional sobre Meio Ambiente, em Estocolmo, Suécia, no ano de 1972; o Seminário Internacional sobre Educação Ambiental em 1975, Belgrado, Iugoslávia; a Conferência Intergovernamental sobre Educação Ambiental de Tbilisi em 1977, Georgia-ex União Soviética, entre outras que tiveram suas recomendações reiteradas em encontros mundiais posteriores (BRASIL, 2002).

As normas e políticas públicas ambientais no Brasil, influenciadas pelos encontros mundiais, tiveram como um dos importantes instrumentos para a viabilização dessa política, a educação ambiental. A recomendação para que as escolas trabalhassem a EA se iniciou, timidamente, na década de 1960, com o Código Florestal - Lei 4.771 de 1965 (revogado pela Lei 12.651/2012), que estabelecia a obrigatoriedade das escolas e outros estabelecimentos públicos comemorarem a semana florestal. Porém, era uma EA limitada ao meio ambiente natural e seus aspectos biológicos, desconsiderando os aspectos socioambientais recomendados para a EA nos eventos pós década de 1960 (BRASIL, 2002). Na década de 1970 foi criada a Secretaria Especial de Meio Ambiente (Sema) pelo Governo Federal, hoje extinta, tendo como uma das suas atribuições "o esclarecimento e a educação do povo brasileiro para o uso adequado dos recursos naturais, tendo em vista a conservação do meio ambiente" (BRASIL, 2018).

No ano de 1981, a PNMA (Lei no 6.938/81) erigiu a EA à categoria de princípio ao recomendá-la em todos os níveis de ensino, inclusive a educação da comunidade, objetivando capacitá-la para participação ativa na defesa do meio ambiente (BRASIL, 1981). Na visão de Sarlet et al. (2017), a partir da implantação da PNMA o Brasil passou a ter um sistema jurídico de proteção ambiental - o direito ambiental -, sem desconsiderar que já havia no país movimentos de valorização ecológica anteriores a essa data, principalmente na década de 1970.

A Constituição Federal de 1988, verdadeiro "paradigma, ambicioso e analítico na proteção do ambiente, embora de caráter antropocêntrico em vias de revisão", fez surgir o "constitucionalismo ecológico 
ou socioambiental" (SARLET et al., 2017). Assim, a Carta Magna erigiu o meio ambiente saudável à categoria de direito fundamental da pessoa humana, ou seja, aquele que existe como garantia mínima em face da vida; apresenta um capítulo inteiro sobre o meio ambiente, impondo a obrigatoriedade da educação ambiental formal em todos os níveis de ensino, como um instrumento para a consecução dos dispositivos legais (BRASIL, 1988).

Em 1992, o Governo Federal criou o Ministério do Meio Ambiente (MMA) e foi realizada no Brasil a II Conferência Internacional das Nações Unidas sobre o Meio Ambiente e Desenvolvimento (RIO-92). Paralelamente a esse evento, ocorreu o Fórum Global de Educação Ambiental, em que foi estabelecido o Tratado de Educação Ambiental para Sociedades Sustentáveis e Responsabilidade Global, sendo a EA entendida como um processo de aprendizado permanente, baseado no respeito a todas as formas de vida e contribuinte para a formação de uma sociedade justa e ecologicamente equilibrada (BRASIL, 2002). De acordo com Branco et al. (2018), o Tratado de Educação Ambiental para Sociedades Sustentáveis e Responsabilidade Global delineia o marco político para o projeto pedagógico da EA brasileira.

A Lei de Diretrizes e Bases da Educação Nacional (LDBEN), Lei no 9.394/1996, apesar de não mencionar o termo 'Educação Ambiental', traz que o ensino fundamental obrigatório terá por objetivo a formação básica do cidadão, mediante a compreensão do ambiente natural e social, do sistema político, da tecnologia, das artes e dos valores em que se fundamenta a sociedade (BRASIL, 1996). No ensino médio, continuou essa mesma proposta, indiretamente, através da "consolidação e o aprofundamento dos conhecimentos adquiridos no ensino fundamental, possibilitando o prosseguimento de estudos" (BRASIL, 1996). Um ano após essa Lei, o MEC elaborou os Parâmetros Curriculares Nacionais (PCNs) incorporando a dimensão ambiental como tema interdisciplinar e transversal nos currículos da Educação Básica (BRASIL, 1997).

Com a Política Nacional da Educação Ambiental(PNEA) - Lei no 9795/1999, institucionalizou-se a EA no Brasil, não obstante já existir antes da sua criação o Programa Nacional de Educação Ambiental (ProNEA), de 1994, elaborado pelo MMA, tendo sua 5a edição publicada em 2018. A lei federal define em seu artigo 1으 que a EA é a construção de conhecimentos, habilidades, competências, valores e atitudes voltados à conservação do meio ambiente saudável e sustentável, tanto pelo indivíduo como pela coletividade (BRASIL, 1999). Sua regulamentação se deu através do Decreto no 4.281, de 25 de junho de 2002.

Em 2012, a educação ambiental brasileira fortaleceu-se ainda mais por meio da Resolução no 2, de 15 de junho de 2012, do Conselho Nacional de Educação(CNE), ao estabelecer as Diretrizes Curriculares Nacionais para a Educação Ambiental (DCNEA), logo após as discussões ocorridas no VII Fórum Brasileiro de Educação Ambiental, realizado em Salvador-Bahia, de 28 a 31 de março de 2012. Tem-se ainda o Plano Nacional de Educação(PNE) - Lei 13.005/2014, que apresenta como uma de suas diretrizes a promoção à sustentabilidade socioambiental (BRASIL,2014). No Plano Estadual de Educação da Bahia-Lei 13.559/2016, essa mesma diretriz repete-se no artigo 2을 inciso IX (BAHIA, 2016).

Em nível nacional, conta-se ainda com recente documento normativo da política de educação básicaa Base Nacional Comum Curricular-BNCC, homologada pelo Ministério da Educação no final de 2017, uma 
resolução de força obrigatória, que trata da questão ambiental em duas de suas dez competências gerais: o conhecimento atrelado à consciência socioambiental e ao princípio ético da sustentabilidade (BRASIL, 2017). Acresce-se a essa normativa dispositivos de hierarquia inferior, como decretos, resoluções, recomendações, instruções normativas, portarias, entre outros, que explicam e aplicam a norma supra e com esta não pode conflitar.

No Estado da Bahia, desde o ano de 2011, conta-se com uma legislação própria sobre a EA, através da Lei 12.056/2011, complementada por normas do Conselho Estadual de Educação (CEE) - Resolução no 11, de 17 de janeiro de 2017, e regulamentada, oito anos depois da sua publicação, pelo Decreto no 19.083 de 06 de junho de 2019. Seu processo de elaboração contou com a participação prévia da sociedade, através de consulta pública aos 26 (vinte e seis) Territórios de Identidade(TI) existentes a época (hoje se conta com $27 \mathrm{TI}$ ), sendo estes unidades contíguas de planejamento das políticas públicas, que abrigam os 417 municípios baianos, formados de acordo com critérios sociais, culturais, econômicos e geográficos (BAHIA, 2018).

Hodiernamente, está em vias de ser implantado na Bahia o novo Currículo da Educação Básica, com espeque na nova Base Nacional Comum Curricular-BNCC. O currículo Bahia apresenta a EA como tema integrador, com amparo legal na PNEA, nas DCNEA, na Resolução do Conselho Estadual de Educação-CEE no 11, de 17 de janeiro de 2017 e na PEEA/BA. A proposta curricular recomenda à comunidade escolar o conhecimento do ProEASE através de site da internet, com o fim de orientar e fortalecer o processo educativo de forma crítica, emancipatória e transformadora (BAHIA, 2018).

\section{Do texto da Lei 12.056/2011 e seu Decreto Regulamentar}

A Lei 12.056/2011 trata sobre a EA em 9 (nove) capítulos e 41 (quarenta e um) artigos, apresentando entre eles o conceito, princípios, objetivos, diretrizes, instrumentos, execução, órgãos gestores (OG) e as áreas temáticas. Conceitua a Educação Ambiental como uma série de procedimentos, reflexões e mudanças a serem cumpridos, visando uma relação sustentável da espécie humana com o seu meio ambiente (BAHIA, 2011). Assim, a sustentabilidade apresenta-se como um verdadeiro fim a ser perseguido, sendo mencionada em outras diversas passagens do texto legal.

A PEEA/BA, embora esteja respaldada pela PNAE, possui em algumas passagens do seu texto uma maior e melhor construção dos seus conceitos, uma vez que leva em conta a evolução epistemológica e metodológica dos últimos anos na área da EA, com mais elementos a uma prática crítica, emancipatória e transformadora, capaz de contribuir para a solução da atual crise socioambiental (RODRIGUES et al., 2016). Dentre os tópicos abordados pela lei em comento, os seus 11 (onze) princípios, com abordagem mais ampla que a PNEA, sintetizam a essência de grande parte do conteúdo da lei, alguns dos quais repetindo-se em outros tópicos, como se verá adiante:

1.Equidade social; 2. Vinculação entre a ética, a educação, o trabalho e as práticas sociais; 3.Solidariedade e cooperação nas diversas relações; 4.corresponsabilidade e compromisso nos processos de ensino e aprendizagem voltados à sustentabilidade; 5.Enfoques humanísticos, holísticos, democráticos e participativos; 6. Respeito e valorização à diversidade; 7. Reflexão crítica; 8 . Contextualização do meio ambiente considerando as especificidades e a interdependência entre os meios natural, socioeconômico e cultural, sob 
o enfoque da sustentabilidade; 9. Sustentabilidade; 10. Diálogos horizontais para a construção do conhecimento com vistas à transformação socioambiental, e 11. Pluralismo de ideias e concepções pedagógicas na perspectiva da multi, inter e transdisciplinaridade e transinstitucionalidade. (BAHIA, 2011)

Os princípios podem ser considerados a pedra fundante, a base, os parâmetros de justiça ou equidade, os mandamentos de otimização com muito peso e importância dentro de um regramento jurídico (NASCIMENTO et al., 2018; MORAIS, 2016). Isso significa que todos os princípios apresentados pela PEEA/BA são tutelados juridicamente, ou seja, têm importância no mundo jurídico, e a sua inobservância às questões ambientais enseja responsabilidades, o que é condizente com a visão de Bosselmann (2015) citado por Morais (2016), ao preceituar que um princípio tem efeito legal quando está previsto em alguma lei.

O princípio da equidade social, ausente nos princípios da PNEA (BRASIL, 1999), está posto para tentar alcançar a justiça socioambiental necessária ao meio ambiente como um todo, e, por que não dizer, nos Territórios de Identidade, já que o estado da Bahia concentra seus 417 (quatrocentos e dezessete) municípios em seus 27 (vinte e sete) diferentes $\mathrm{TI}$, cada um com as suas especificidades, em seus microssistemas. Silva (2016) entende que a equidade visa atenuar as desigualdades, tratando de forma desigual e justa os grupos que estão em desvantagem a outros por circunstâncias variadas. Dessa forma, tratar e atender os desiguais na medida das suas desigualdades promove a efetividade do princípio da equidade social.

Quando a PEEA/BA coloca como princípio a 'reflexão crítica' sugere a superação da visão naturalista de EA por uma visão de meio ambiente com a inter-relação entre pessoas, sociedade e ambiente. Essa visão ampla sobre as questões ambientais, capaz de compreender o mundo e agir nele, forma hoje o que se chama 'sujeito ecológico' (CARVALHO, 2004).

Em seu 8o princípio, apresenta-se uma educação ambiental voltada aos contextos natural, social, econômico e cultural com foco na sustentabilidade. Necessário também o olhar para o contexto político, omisso nesse dispositivo da Lei. Corrobora esse mesmo entendimento Nascimento (2012), citado por Tiriba (2014), ao pontuar que a sustentabilidade apoiada somente na tríade ecológico-econômico-social é despolitizada, pois, na perspectiva crítica, o embate político é necessário. Ainda, na visão de Rosa et al., (2018) a política ambiental pode ser considerada como o conjunto de ações efetivas utilizadas pelo poder público para a qualidade do meio ambiente.

O princípio do enfoque holístico sobre o meio ambiente reforça a ideia de que é preciso uma nova visão sobre a natureza, em que todos os seus elementos estejam interconectados, como bem assevera Capra (2006), o reconhecimento da interconexão entre os diferentes sistemas envolvidos nos processos de sustentabilidade, tão necessários à existência saudável.

Observa-se que a sustentabilidade, ausente como princípio na PNEA, tem grande relevância nos princípios da PEEA/BA, pois tanto o é como se inter-relaciona com outros, a exemplo dos princípios da corresponsabilidade e o compromisso individual e coletivo da educação voltados à sustentabilidade; e o da contextualização do meio ambiente, considerando os diversos contextos territoriais e a interdependência entre os meios natural, socioeconômico e cultural sob o enfoque da sustentabilidade (BAHIA, 2011).

A sustentabilidade se apresenta como princípio quando a Lei determina que a PEEA/BA "será 
conduzida pelos seguintes princípios: [...]sustentabilidade como garantia ao atendimento das necessidades das gerações atuais, sem comprometimento das gerações futuras, valorizadas no processo educativo" (BAHIA, 2011). Com base nisso, apresenta um meo conceito de sustentabilidade respaldado no artigo 225 da Constituição Federal de 1988 que, por sua vez, tomou emprestado o conceito de desenvolvimento sustentável apresentado pela Comissão Mundial sobre Meio Ambiente e Desenvolvimento (CMMAD) no Relatório de Bruntland (CMMAD, 1991).

O conceito de desenvolvimento sustentável, como aquele que atende às necessidades do presente sem comprometer a capacidade das gerações futuras de atenderem as suas próprias necessidades (CMMAD, 1991), constitui-se em uma visão antropocêntrica, vez que apresenta a sustentabilidade sob a ótica da sobrevivência humana. Esse significado é reduzido e contestado pela Ecologia Humana, pois "analisar a sustentabilidade apenas de uma espécie incorre no erro da visão atomicista que a própria Ecologia Humana tenta combater" (ALVIM, 2014).

Quanto ao pluralismo de ideias e concepções pedagógicas, recomenda-se romper os muros da disciplinaridade e promover uma educação ambiental disseminada por todas as áreas do conhecimento, permeando todos os componentes curriculares em todas as séries e níveis de ensino. Contudo, a Lei apresenta as concepções pedagógicas e não esclarece os seus significados, tornando-se conceitos abstratos que estabelecem regras mas não indicam a forma de efetivá-las. São termos usados com frequência, deixando dúvidas quanto a compreensão pelo próprio legislador.

Quanto aos outros princípios, reforçam à atenção aos aspectos sociais, colaborativos, participativos, respeito à diversidade e da não hierarquização na construção do conhecimento para transformar a realidade socioambiental (BAHIA, 2011). O aspecto social entra para a equação do equilíbrio ambiental, tendo em vista que, hodiernamente, a desigualdade social é considerada um dos mais graves problemas ambientais a serem enfrentados por pessoas, povos e nações (TIRIBA et al., 2014).

Os objetivos da Lei, contidos no artigo 4으, reforçam a compreensão holística do meio ambiente envolvendo diversos aspectos, inclusive os espirituais e psicológicos, invocando a esfera subjetiva do ser humano; a formação ética sobre as questões socioambientais; o incentivo às participações comunitárias na defesa do meio ambiente, como exercício de cidadania; estímulo a capacitação de pessoas para atuar em órgãos colegiados; a integração entre os diversos setores do estado; o compartilhamento das informações socioambientais; fortalecimento da cidadania, da diversidade e solidariedade para o surgimento de uma sociedade sustentável (BAHIA, 2011). Com isso, compreender os mecanismos sociais, éticos, econômicos, políticos e culturais da questão ambiental faz com que a bandeira da EA não seja distorcida e superficial, ou até mesmo direcionada a atribuir responsabilidades à apenas um setor da sociedade.

As diretrizes da Lei, contidas no artigo 5, são as instruções ou indicações para se elaborar um plano na esfera ambiental e devem corresponder: a produção, consumo e integração com as ciências e tecnologias sustentáveis; redes de EA colaborativas, integrando o contexto local e global; criação ou empoderamento de núcleos de EA nas instâncias públicas e privadas; integração com a área de saúde; incentivo à pesquisa e à produção de material de EA, específicos a cada realidade do território baiano (BAHIA, 2011). Logo, as 
diretrizes traçam os caminhos a serem percorridos pela EA para o alcance da sustentabilidade, considerando a realidade local, a integração da EA com outras ciências e a formação de coletivos em EA.

Em seu artigo 6ㅇ, a PEEA/BA apresenta as linhas de atuação inter-relacionadas que devem ser priorizadas na EA: formação e capacitação de pessoas; desenvolvimento de estudos, pesquisas e experimentações; produção e divulgação de material educativo; acompanhamento e avaliação continuada e disponibilização permanente de informações.

Ademais, a capacitação, parte do processo de formação de pessoas, tem por diretrizes: a incorporação da dimensão ambiental e sustentável na formação, especialização e atualização dos educadores de todos os níveis e modalidades de ensino e dos profissionais de todas as áreas, com destaque para as áreas de meio ambiente e gestão ambiental; o atendimento à demanda dos diversos segmentos da sociedade para a capacitação em Educação Ambiental (BAHIA, 2011).

As linhas de atuação indicam como se dará a divulgação do conhecimento para o trabalho com a EA, desde a formação e capacitação de professores a de outros profissionais e diversos segmentos da sociedade que trabalham a EA, informalmente. As ações de estudos, pesquisas e experimentações em EA voltar-se-ão para o desenvolvimento de instrumentos, metodologias, alternativas curriculares, apoio às pesquisas, iniciativas e experiências em EA, identificação de problemas e construção coletiva de alternativas para sociedades sustentáveis (BAHIA, 2011).

Nesse sentido, os profissionais da educação precisam estar instrumentalizados através do conhecimento ambiental na tentativa de provocar a transformação da realidade, integrando teoria e prática. Mesmo ciente de que o mecanismo externo da Lei não é suficiente para a sua efetividade, há de se considerar que "conhecer e entender a Lei são os passos iniciais" (SEMA, 2012, p. 9). De acordo com Carniatto et al. (2018), o conhecimento é importante para formar opinião; cita que "É preciso conhecer para agir no mundo", "Só faz sentido conhecer para emancipar" (BOFF, 1999, citado por CARNIATTO et al., 2018).

Embora a PEEA/BA recomende a formação, especialização e atualização dos educadores em todos os níveis e modalidades de ensino na seara ambiental, o que se evidencia em algumas decisões do Tribunal de Justiça da Bahia (TJBA) é a negativa da administração pública em conceder licença remunerada para os profissionais da educação básica cursarem pós-graduação(mestrado e doutorado), inclusive, na área de EA, tendo o Poder Judiciário que decidir sobre a concessão da licença, amparado na Carta Magna de 1988 e na Lei de Diretrizes e Bases da Educação Nacional. Pode-se, ainda, encontrar amparo no Plano Nacional de Educação(PNE), que prevê a formação continuada dos professores (BRASIL, 2014).

Quanto aos instrumentos, no seu artigo 7ํㅡ. a PEEA/BA apresenta o Programa Estadual de Educação Ambiental-PEA/BA, o Diagnóstico Estadual de Educação Ambiental-DEEA e o Sistema Estadual de Informações sobre a Educação Ambiental-SEIEA. De acordo com o regramento normativo, O PEA/BA é o conjunto de diretrizes para a implementação da PEEA/BA e referência para a elaboração de programas em EA em todo o Estado; O DEEA/BA é o resultado da análise da situação atual da Educação Ambiental no Estado da Bahia; Já o SEIEA/BA organiza a coleta, o tratamento, o armazenamento, a recuperação e a divulgação de informações sobre EA e fatores intervenientes em sua gestão, em todo Estado (BAHIA, 2011). 
A Lei 12.056/2011 conceitua a EAF como aquela desenvolvida no âmbito das instituições públicas, privadas e comunitárias de ensino, englobando a Educação Básica, Educação Superior, Educação Especial, Educação Profissional, Educação de Jovens e Adultos, Educação para o Idoso; Educação Indígena, Educação Quilombola e Educação do Campo, cabendo aos sistemas formais de educação promoverem a inserção da Educação Ambiental no Regimento Escolar e no Projeto Político Pedagógico das escolas, em todos os níveis e modalidades de ensino, inclusive, nos planos de aulas (BAHIA, 2011; CEE, 2017). Em se comparando com a PNEA, a definição aqui apresentada estende-se as instituições comunitárias de ensino e abrange um público maior como os indígenas, quilombolas, idosos e educação do campo.

Na visão de Portugal et al. (2018), a educação ambiental nas escolas, voltada para a sustentabilidade socioambiental, não é tarefa fácil, pois demanda tempo, estudo, participação individual e coletiva, boa vontade política, diálogo, equidade social, tendo como pilares para a mudança de paradigmas, o currículo, a gestão, o espaço físico e a relação com a comunidade escolar.

Na modalidade formal de EA a Lei diz pouco. O que foi aprimorado consta no PEA/BA, no ProEASE, na Resolução do CEE/BA e no Decreto Regulamentar. Este último normatiza quais as instâncias e instrumentos responsáveis pela implementação da Lei na educação formal, seja pública ou privada, cabendo à Secretaria de Educação da Bahia (SEC/BA): criar Grupos de Trabalho de Educação Ambiental nos Núcleos Territoriais de Educação-NTE para a implantação da PEEA/BA; inserir a temática da EA na jornada pedagógica, considerando os documentos existentes no Estado, em especial o ProEASE; Inserir a EA no Regimento Escolar e no Projeto Político Pedagógico-PPP; promover formação continuada aos professores e utilizar os preceitos da EA na atividades da gestão escolar, a exemplo de uma simples compra para guarnecer as unidades de ensino (BAHIA, 2019).

A execução da PEEA/BA cabe aos órgãos e instituições educacionais públicos e privados do sistema de ensino, aos órgãos e entidades integrantes do Sistema Estadual de Meio Ambiente (SISEMA), à Comissão Interinstitucional de Educação Ambiental-CIEA, aos outros órgãos e entidades públicos, entidades não governamentais, entidades de classe, meios de comunicação e demais segmentos da sociedade. Já a coordenação da PEEA/BA é feita por um órgão gestor, dirigido pelos secretários do meio ambiente e da educação do estado da Bahia, que poderá consultar, quando necessário, a CIEA, órgão colegiado de grande importância nas políticas públicas de EA da Bahia, criado por Lei em 2006 (BAHIA, 2011).

A Lei prevê, timidamente, a alocação de recursos para o investimento nas políticas públicas de EA, desde que obedecidos alguns critérios, dentre os quais o da economicidade, que avalia custo/benefício do projeto, cabendo ao Órgão Gestor e a CIEA buscarem recursos privados e públicos em projetos de EA, inclusive, sugere a aplicação de recursos de Fundos Especiais (BAHIA, 2011). Contudo, na Bahia não existe um Fundo Especial de Educação Ambiental. O que existe é o Fundo Especial de Meio Ambiente, da Secretaria Estadual de Meio Ambiente (SEMA), que disponibiliza recursos financeiros para os projetos na área de meio ambiente (SEMA, 2019). Em nível nacional, existe o Fundo Nacional de Meio Ambiente (FNMA), criado em 1989, no MMA.

Importante mencionar que está em tramitação na Câmara dos Deputados o projeto de Lei no 
1228/2015, que prevê a criação específica do Fundo Nacional de Educação Ambiental-FNEA. Enquanto a Lei não se concretiza, o financiamento para as políticas de EA nas escolas conta com o Fundo Nacional de Educação-FNDE, que disponibiliza recursos financeiro através do Programa Dinheiro Direto nas Escolas-PDDE, de acordo com dados do MMA (2017).

O documento "Fontes de financiamento para a educação ambiental", do MMA (2017), atesta que os recursos disponíveis para investimento nessa área cresceram, contudo, a falta de conhecimento e da propagação da existência de recursos para as políticas de educação ambiental, ou a inadequação na elaboração de projetos, tornam-se empecilhos para as ações voltadas à educação ambiental e desenvolvimento socioambiental.

Apesar do contido no documento supra, atualmente o que se vê é a mitigação das políticas públicas ambientais no cenário da gestão da política nacional. Na visão de Tozoni-Reis (2019), o Brasil vive tempos sombrios quanto às políticas ambientais e a 'secundarização' da proteção ambiental. Isso põe em risco o princípio da proibição ao retrocesso ambiental, fundamento este que faz valer o direito-dever ao meio ambiente ecologicamente equilibrado.

Depois de 8(oito)anos de publicada, com a recomendação de ser regulamentada pelo Poder Executivo em 180(cento e oitenta) dias da sua publicação (BAHIA, 2011), a PEEA teve sua regulamentação publicada no dia 07 de junho de 2019, através do Decreto 19.083 de 06 de junho 2019 do governo do estado da Bahia, tornando a Lei mais detalhada e solicitando a atenção do poder público administrativo para a sua execução.

No DR da Lei em análise não há menção a todos os dispositivos da Lei. Ele trata da atuação dos instrumentos da PEEA/BA(o programa, o diagnóstico e o sistema de informações); preceitua que o PEA deverá ser revisado a cada 08(oito) anos com a participação da sociedade, coordenado pelo órgão gestor (OG) da PEEA, com apoio e orientação da Comissão Interinstitucional (CIEA);apresenta as atribuições da CIEA; atribui à Secretaria de Educação a incumbência da implantação da PEAA na educação formal, que deverá promover processos continuados e permanentes de formação de professores em EA (BAHIA, 2019).

O DR estabelece como se dará a política de EA nos eixos temáticos das políticas públicas, unidades de conservação, saneamento ambiental, licenciamento e educação ambiental formal. Impõe ao OG da PEEA elaborar orientações para o desenvolvimento de ações e programas municipais de EA e o incentivo a implementação de um programa que objetive a maior eficiência socioambiental no âmbito do Poder Público Estadual, por meio de, por exemplo, seminários, oficinas e encontros (BAHIA, 2019).

\section{CONCLUSÕES}

O bem jurídico tutelado pela Lei 12.056/2011 é a Educação Ambiental, impondo grande responsabilidade à educação formal quanto à efetividade dessa modalidade de educação, constituindo-se em mais um instrumento em prol do trabalho escolar na seara ambiental. E o grande desafio que se apresenta é garantir a eficácia da Lei, ou seja, passar da teoria à prática, fazer-se cumprir a Lei, muitas vezes condicionada a fatores políticos-administrativos contrários a sua efetividade. 
A PEEA/BA apresenta-se mais ampla do que a PNEA quando discorre sobre o seu texto em nove capítulos e quarenta e um artigos, números bem maiores que a Lei Federal; centra-se na territorialidade em respeito a diversidade e as diferentes realidades nos Territórios de Identidade ( $\mathrm{TI}$ ); dá relevo à democratização na produção e divulgação do conhecimento ambiental e ao princípio da sustentabilidade; e pretende disseminar a educação ambiental formal a uma parcela maior da sociedade. No entanto, pelo lapso temporal de mais de 8(oito) anos para a sua regulamentação, através do Decreto Regulamentar 19.083/2019, revela-se que a administração pública não elegeu a política de educação ambiental como prioridade.

De uma maneira geral, como foram apresentados os dispositivos da Lei, pode-se dizer que a PEEA/BA busca, através da educação ambiental, o alcance do princípio da sustentabilidade socioambiental, fundamento muito recomendado nesse regramento. Para tanto, faz-se necessário o desenvolvimento de uma compreensão integrada de meio ambiente, incluindo, além dos aspectos naturais, sociais e econômicos, os culturais e políticos, sendo este último mitigado no texto legal.

No contexto da Educação Ambiental Formal, a Lei prevê tornar as escolas um espaço educador sustentável, no intuito de criar e desenvolver uma nova cultura, com valores excludentes da degradação ambiental. Contudo, essa ideia vai esbarrar em muitos fatores condicionantes dentro do próprio sistema educacional, seja pela falta de conhecimento ou falta da eficácia das políticas públicas voltadas à formação continuada dos profissionais da educação.

A Lei estadual não determina nenhum mecanismo de fiscalização para o seu cumprimento, o que não impede seja feita pelo Ministério Público, como fiscal da Lei (custus legis), tendo em vista que a EA é matéria de interesse público ou social. Além disso, a autoridade competente responsabiliza-se em caso de omissão no cumprimento do ensino obrigatório ou se ofertá-lo irregularmente, sendo este preceito constitucional.

É bem persuasiva a recomendação da PEEA/BA no que tange à formação continuada dos docentes na área de EA em um processo permanente, duradouro e de democratização na produção e apropriação do conhecimento. Entretanto, tal premissa está somente no mundo do dever ser, na letra da Lei. O que se evidencia é uma resistência por parte da administração pública do estado da Bahia no incentivo à formação continuada dos profissionais da educação básica, a exemplo dos docentes que recorrem com frequência ao Poder Judiciário para cursarem mestrado ou doutorado, e ver garantido o direito ao aperfeiçoamento profissional previsto na legislação pátria. O texto do decreto regulamentar da Lei limita-se a determinar que a SEC/BA realize a formação continuada dos professores em matéria ambiental.

Com base nas observações deste estudo, sugere-se a necessidade de outras produções sobre a PEEA/BA, uma vez que as discussões sobre essa Lei são inexpressivas no mundo acadêmico e científico, o que se percebeu pela falta de publicações sobre a normativa em periódicos respaldados. A comunicação entre os cursos de graduação, pós-graduação e educação básica seria, possivelmente, uma alternativa para potencializar a EAF, com a consequente promoção de reflexões favoráveis à sustentabilidade nos seus vários aspectos, na busca da concretização de uma EA crítica, reflexiva e promotora da difícil mudanças de valores e atitudes que o cenário ambiental e societário requer. 


\section{REFERÊNCIAS}

ALVIM, R. G.. Bases da Ecologia Humana. In: ALVIM, R. G.; BADIRU, A. I.; MARQUES, J.. Ecologia Humana: uma visão global. Feira de Santana: UEFS, 2014. p.21-37.

BAHIA. Decreto 19.083 de 07 de junho de 2019.

Regulamenta a Lei № 12.056, de 07 de janeiro de 2011, que institui a Política de Educação Ambiental do Estado da Bahia, e dá outras providências. Salvador: DOE, 2019.

BAHIA. Documento Curricular Referencial da Bahia para Educação Infantil e Ensino Fundamental. Salvador: SEC, UNDIME, 2018.

BAHIA. Lei n.12.056 de 07 de janeiro de 2011. Institui a Política de Educação Ambiental do Estado da Bahia, e dá outras providências. Salvador: SEMA, 2012.

BAHIA. Lei n.13.559 de 11 de maio de 2016. Aprova o Plano Estadual de Educação da Bahia e dá outras providências. Salvador: DOE, 2016.

BAHIA. Programa de Educação Ambiental do Sistema Educacional da Bahia - ProEASE. 2 ed. Salvador: SEC, 2015.

BAHIA. Resolução n.11, de 17 de janeiro de 2017. Dispõe sobre a Educação Ambiental no Sistema Estadual de Ensino da Bahia. Salvador: CEE, 2017.

BAHIA. Tribunal de Justiça da Bahia. Mandado de Segurança Cível n.8007971-55.2018.8.05.0000/BA. Salvador: DOE, 2019.

BAHIA. Tribunal de Justiça da Bahia. Mandado de Segurança Cível n.8012937-61.2018.8.05.0000/BA. Salvador: DOE, 2019.

BARDIN, L.. Análise de conteúdo. Lisboa: 70, 2002.

BENJAMIN, A. H. V.. Introdução ao direito ambiental brasileiro. Revista de Direito Ambiental, São Paulo, v.4, n.14, 1999.

BOFF, L.. Saber Cuidar: ética do humano, compaixão pela terra. Petrópolis: Vozes, 1999.

BOSSELMANN, K.. O Princípio da Sustentabilidade: transformando direito e governança. São Paulo: Revista dos Tribunais, 2015.

BRANCO, E. P.; ROYER, M. R.; BRANCO, A. B. D. A Abordagem da Educação Ambiental nos PCNs, nas DCNs e na

BNCC. Nuances: estudos sobre Educação, v.29, n.1, p.185203, 2018. DOI:

http://doi.org/10.32930/nuances.v29i1.5526

BRASIL. Base Nacional Comum Curricular-BNCC. Brasília: MEC, 2017.

BRASIL. Constituição da República Federativa do Brasil de 1988. Brasília: DOU, 1988.

BRASIL. Educação Ambiental Legal. Brasília: MEC, 2002.

BRASIL. Educação ambiental por um Brasil sustentável: ProNEA, marcos legais e normativos. Brasília: MMA, 2018.
BRASIL. Fontes de financiamento para a educação ambiental. Brasília: MMA, 2017.

BRASIL. Lei n.13.005, de 25 de junho de 2014. Aprova o Plano Nacional de Educação - PNE e dá outras providências. Brasília: DOU, 2014.

BRASIL. Lei n.6.938, de 31 de agosto de 1981. Dispõe sobre a Política Nacional do Meio Ambiente, seus fins e mecanismos de formulação e aplicação, e dá outras providências. Brasília: DOU, 1981.

BRASIL. Lei n.9.394, de 20 de dezembro de 1996. Estabelece as diretrizes e bases da educação nacional. Brasília: DOU, 1981.

BRASIL. Lei n.9.795, de 27 de abril de 1999. Dispõe sobre a educação ambiental, institui a Política Nacional de Educação Ambiental e dá outras providências. Brasília: DOU, 1999.

BRASIL. Parâmetros Curriculares Nacionais: introdução aos parâmetros curriculares nacionais. Brasília: MEC, 1997.

BRASIL. Projeto de Lei n.1228/2015. Institui o fundo Nacional de Educação Ambiental - FNEA e dá outras providências. Brasília: Câmara dos Deputados, 2015.

BRASIL. Resolução n.2, de 15 de junho de 2012. Estabelece as Diretrizes Curriculares Nacionais para a Educação Ambiental. Brasília: CNE, 1999.

BRASIL. Senado Notícias. Conceitos de sanção, promulgação e publicação. Brasília: DOU, 2019.

BRASIL. Senado Notícias. Conceito de vacatio legis. Brasília: DOU, 2019.

CAPRA, F.; BERRY, W.; ABLEMAN, M.. Alfabetização ecológica: a educação das crianças para um mundo sustentável. São Paulo: Cultrix, 2006.

CARNIATTO, I.; MORAIS, M. M.; OLIVEIRA, J. B.;

OTTAVIANO,S.. Educação Ambiental: Fomento para a Gestão Integrada de Bacias Hidrográficas. In: BAGANHA, D. E.; VIEIRA, E. R.; MORTELLA, R. D.; ROSA, M. A.. Educação ambiental rumo à escola sustentável. Curitiba: SEED, 2018. p.41-51.

CARVALHO, I. C. M.. Educação Ambiental: a formação do sujeito ecológico. São Paulo: Cortez, 2004.

CMMAD. Comissão Mundial Sobre Meio Ambiente e Desenvolvimento. Nosso futuro comum. Rio de Janeiro: Fundação Getúlio Vargas, 1991.

COSENZA, A.; KASSIADOU, A.; SANCHEZ, C.. Educação Ambiental em Direitos Humanos: necessárias articulações a partir da justiça ambiental e da ecologia política. In: SILVA, A. M. M.; TIRIBA, L.. Direito ao ambiente como direito à vida: desafios para a educação em direitos humanos. São Paulo: Cortez, 2014. p.21-46.

GODOY, A. S.. Pesquisa qualitativa-Tipos fundamentais. Revista de Administração de Empresas, São Paulo, v.35, n.3, 
p.20-29, 1995.

MORAIS, F. S.; IVANOFF, F.. A sustentabilidade como princípio jurídico no direito brasileiro. Revista Jurídica Direito e Paz, São Paulo, n.35, p.50-66, 2016.

NASCIMENTO, E. P.. Trajetória da sustentabilidade: do ambiental ao social, do social ao econômico. Estudos Avançados, v.74, n.26, 2012.

NASCIMENTO, R. C.; SANTOS, C. A. B.; OLIVEIRA, M. R.; LIMA M. A. G.; SÁ, U. R. N.. O princípio da sustentabilidade na lei da merenda escolar. Revista Ouricuri, Juazeiro, v.8, n.1, p.11-24, 2018.

PORTUGAL, S.; SORRENTINO, M.. Diretrizes Curriculares Nacionais para a Educação Ambiental e suas contribuições à escola sustentável. In: BAGANHA, D. E.; VIEIRA, E. R.; MORTELLA, R. D.; ROSA, M. A.. Educação ambiental rumo à escola sustentável. Curitiba: SEED, 2018. p.9-17.

RODRIGUES, C. S.; SANTOS, C. C.; PEREIRA, N. R.. Educação ambiental como política pública no Estado da Bahia: um olhar sobre a PEEA-BA. REMEA: Revista Eletrônica do Mestrado em Educação Ambiental, Rio Grande, v.33, n.2, p.286-301, 2016. DOI: https://doi.org/10.14295/remea.v33i2.5714.

ROSA, A.; CAVALCANTI, M.. Direitos humanos, meio ambiente e educação. Revista Augustus, Rio de Janeiro, v.23, n.46, p.136-156, 2018.

DOI: https://doi.org/10.15202/1981896.2018v23n46p136.

SARLET, I. W.; MACHADO, P. A. L.; FENSTERSEIFER, T.. Constituição e Legislação Ambiental Comentadas. São Paulo: Saraiva, 2015.

SILVA, A.. Mobilidade urbana e equidade social: possibilidades a partir das recentes políticas de transporte público na Metrópole do Rio de Janeiro. GOT, Porto, n.10, p.293-317,2016. DOI: http://dx.doi.org/10.17127/got/2016.10.014

TIRIBA, L.; PROFICE, C.. O direito humano à interação com a natureza. In: SILVA, A. M. M.; TIRIBA, L.. Direito ao ambiente como direito à vida: desafios para a educação em direitos humanos. São Paulo: Cortez, 2014. p.47-77.

TOZONI-REIS, M. F. C.. Sobre educar e transgredir. Revista Ciência e Educação, Bauru, v.25, n.1, p.3-4, 2019. DOI: http://dx.doi.org/10.1590/1516-731320190010001

A CBPC - Companhia Brasileira de Produção Científica (CNPJ: 11.221.422/0001-03) detém os direitos materiais desta publicação. Os direitos referem-se à publicação do trabalho em qualquer parte do mundo, incluindo os direitos às renovações, expansões e disseminações da contribuição, bem como outros direitos subsidiários. Todos os trabalhos publicados eletronicamente poderão posteriormente ser publicados em coletâneas impressas sob coordenação da Sustenere Publishing, da Companhia Brasileira de Produção Científica e seus parceiros autorizados. Os (as) autores (as) preservam os direitos autorais, mas não têm permissão para a publicação da contribuição em outro meio, impresso ou digital, em português ou em tradução. 